\title{
Why Do Students Make Errors when Solving Problem in Semiotic Representation?
}

\author{
$1{ }^{\text {st }}$ Christine W. Suryaningrum \\ Universitas Negeri Malang \\ Malang, Indonesia \\ corresponding author: \\ christine.wulandari.1603119@ students. \\ um.ac.id \\ $4^{\text {th }}$ Hery Susanto \\ Universitas Negeri Malang \\ Malang, Indonesia \\ hery.susanto.fmipa@um.ac.id
}

\author{
$2^{\text {nd }}$ Purwanto \\ Universitas Negeri Malang \\ Malang, Indonesia \\ purwanto.fmipa@um.ac.id
}

\author{
$3^{\text {rd }}$ Subanji \\ Universitas Negeri Malang \\ Malang, Indonesia \\ subanji.fmipa@um.ac.id
}

\begin{abstract}
Error in learning mathematics means an inappropriateness of someone in determining the solution of a problem, either in the concepts or its completion procedures. Semiotics means signs or symbols. The use of symbols is the concept of one's thinking in using symbols and representing certain meaning. Problem-solving in semiotic representation is a method for students to solve a problem in the form of algebra, graphics, tables, everyday language, body language and computer language (e.g., Basic, Pascal). This paper sheds new light on analyzing students' error in determining the coefficient of a variable from Two-Variable Linear Equation System. In an effort to meet that purpose, this study conducted a qualitative research with an explorative descriptive approach. Subjects in this study are ten students of 3rd semester in one of the private universities in Jember. The subject was intervened one nonroutine problem, i.e., the matter of determining the coefficient of a variable from Two-Variable Linear Equation System. The findings of this study revealed that in the early stages of problem-solving, students try to find the coefficient of a variable by the method of elimination. In the final stages, there are three common mistakes which are identified in this research. Firstly, the students do not understand the purpose of the problem, so they could not find the coefficient of the variable should not use the letting, Secondly, students do not realize that substitute the variable coefficients of the system of linear equations least two grades, but the number was not up. Lastly, students do not resolve the problem according to the appropriate procedure, so they could not find the coefficient values based on the requirements of the problem.
\end{abstract}

Keyword-- Semiotic Representation, Linear Equation System, Problem-solving skills, Mathematics Education

\section{INTRODUCTION}

Errors are actions that deviate from predefined rules. Error in learning mathematics means that an inappropriateness of someone in understanding the material which yields an inaccuracy in determining the solution of a problem, either in the concepts or its completion procedures. Research conducted by Sandhu shows that the errors made by the students are not solely because the students do not understand the material, due to the fact that the students already know the stage of completion of any problems, worse still they make errors in performing the calculations or substitute specific value [1].
The error which is often constituted by students must be fixed so that students would not make the same error. This discourse is in line with the results of research by Lannin, et.al. who showed that students always learn from the errors that they have made, and then the students will have a better understanding of the material [2]. By learning from errors, the students also would not repeat the errors if students are exposed to the same or similar problems. Students often make errors when they represent mathematical ideas. Representation is a vital element in the theory of teaching and learning in mathematics, because the representation or symbolic system is not only used in mathematics, but also in syntax and semantics, which are plentiful, varied, and universal.

The representation ability is one of the capabilities that students must possess in mathematics learning because representational skills play an important role in mathematical problems [3]. Representation will provide multi perception so that the students will be able to develop the process of thinking. In the same way, problem representation also looks intricate and complicated which can be viewed in more accessible and more straightforward way.

The students' ability to represent problem of various forms can provide an opportunity to construct a different approach to the same problem so that students do not focus on one idea and one representation [4]. Representation will help students in organizing the process of thinking. In this case, representations help students in crafting abstract mathematical ideas become more concrete and real. The use of multiple representations in mathematics learning can provide retention of understanding of mathematical concepts and it can arouse students' interest in mathematics. Lesh, Post and Behr (in Hwang et al.) divide that representation used in mathematics education in five types, including object representation real world, concrete representation, representation of spoken language or verbal, image or graphic representation, and the representation of arithmetic symbols. This study of symbols or signs is called semiotics [5-6].

Semiotics is derived from the Greek, semeion, which means a mark or sign. A sign is a physical form - e.g., codes, signals, symbols, words, icons, objects, and gestures- that can 
be captured by the five human senses and is something that represents something other than the sign itself. Establishing this sign is undertaken for the sake of communication. Students can represent their mathematical ideas through symbols or signs. The most important thing in formatting a sign is how the emerged meaning from a mark when it was used by people when communicating.

Semiotic dimensions were used in the teaching and learning of mathematics. In mathematics, student learn at the first time to operate exclusively with signs, they investigate the world objects and concrete activities can be represented and understood mathematically, they are frequently confronted by the problem which is different represents the previous situation, and they can see that such representation changes often me come up with new insights [7]. Almost all mathematical learnings use signs as the learning material. By interpreting and transforming the signs, we developed a new mathematical knowledge.

A growing body of literature has evaluated the list of semiotic diagrams for geometry and it indicates that the list can be used as an empirical study in a geometry textbook diagram [8]. Batanero and Contreras convey that semiotic conflicts arise from a pre-service teacher is confusion between simple probability and the probability of an event, the confusion between mathematical objects (e.g., probability and frequency), difficulty in reading the two-way table and confusion in the use of the formula [9]. In comparison, Tarasenkova and Kovalenko expound that semiotics and semantics of mathematical tasks arranged in teaching mathematics for elementary school students education [10]. Tarasenkova, notwithstanding, reveals a new aim in teaching mathematics is ensuring of the unity of the two processes: first the formation of subject knowledge, skills, and abilities, both of which mark experience independently and the students' symbolic activities [11]. In addition, semiotic components could also appear in generalization pattern activity include gesture, words, and symbols [12]. This suggest that Uzuna and Arslanb concluded that students can understand the material that has not been understood by the semiotic representation [13].

\section{METHODS}

The type of research used is qualitative research with explorative, descriptive approach. The instrument used in this study consisted of researchers themselves as the main instrument that researchers and auxiliary instruments that semiotic representation assignment sheet and guide the interview. The subject was given a non-routine matter that is a matter of determining the coefficients of the variables of SPLDV.

Subjects were selected based on the worksheet in the problem-solving task semiotic representation, do interviews if there is a missed information or the information that needs to be reconfirmed with the aim to classify subjects into specific characteristics. Furthermore, from each of these characteristics are taken at least two people to be the subject of research. From the results of the election subject 3rd semester, ten students obtained one of the private universities in Jember. Of the ten students there are three answers to students classified as the characteristics do not understand the question, four answers of students classified as separating characteristic variables and coefficients, three student answers pertained as separating characteristic of the variables to find the coefficient.

The data in this study is data results of students in doing work in a problem-solving task sheet semiotic representation and interview data. The collected data were analyzed using qualitative analysis techniques. In general, the analysis process related to the stages Creswell which includes: data reduction, categorization of data, synthesis, and ends with the preparation of a working hypothesis [14].

\section{RESULTS AND DISCUSSION}

According to the student's answers can be grouped into three characteristics of error. To solve the problem, student eliminating the variable $\mathrm{x}$ in the early stage, then the student experience confusion to find the value of the coefficients of the variables requested by the matter.

From the subject's answer in $\mathrm{K} 1$, the subject instantly assumes the value $b$. After letting the value of $b$, the subject of substituting the value of $b$ into the equation 2 . The next phase of the subject of elimination of variable $x$ by multiplying the first equation by 2 and multiplying the equation 2 to 1 , to obtain the value of $y=1$ and substituting the value of $y=1$ into the equation 1 for find the value of $x$, i.e., $x=1$. The subject at $K 1$ concludes the solution of the problem is $(1,1)$. The following answers are the subject in characteristic $1(\mathrm{~K} 1)$.

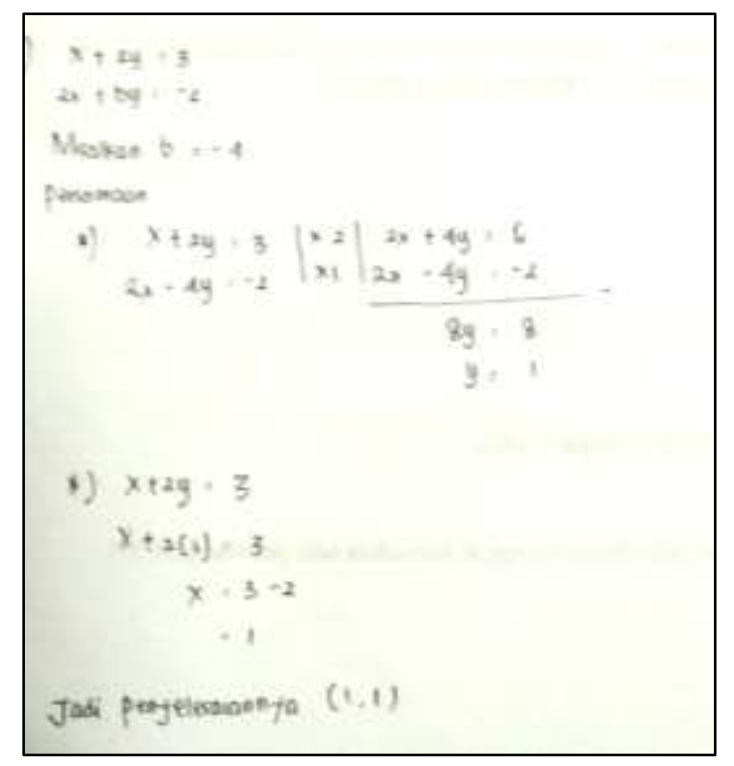

Fig. 1. Subjects were classified in the characteristics of do not understand the question.

From the subject's answer in K1, the subject instantly assumes the value $b$. After letting the value of $b$, the subject of substituting the value of $b$ into the equation 2 . The next phase of the subject of elimination of variable $x$ by multiplying the first equation by 2 and multiplying the equation 2 to 1 , to obtain the value of $y=1$ and substituting the value of $y=1$ into the equation 1 for find the value of $x$, i.e., $\mathrm{x}=1$. The subject at $\mathrm{K} 1$ concludes the solution of the problem is $(1,1)$. 
Based on the interview subject on the $\mathrm{K} 1$ data showed that subjects read about quickly, then the subject Letting $b=-4$ is easier to simplify the equation by using elimination. After being asked to re-read the questions carefully, new subjects realized that the questions in the matter are to determine the coefficients of the variables of a system of linear equations, not to seek resolution of the system of linear equations. The following is an excerpt from an interview with the subject on $\mathrm{K} 1$.

P: from the answers, you know what you are looking for?

$S$ : the value of $x$ and $y$

Q: What is $x$ and $y$ ?

S: variable mam ...

P: take a look at the question once again, what is asked on the matter?

$\mathrm{S}$ : determines the value $\mathrm{b}$ of the system of linear equations.

Q: What's b?

S: the coefficient of the variable.

Q: Then why are you looking for the value of variables?

$\mathrm{S}: \mathrm{mmmm}$.... yes yes mam ...

From the results of answers and interviews on the $\mathrm{K} 1$ subject, it can be interpreted that subject does not understand the intent of the problem so that the subject seeks completion instead of the variable coefficient of the system of linear equations. Errors that occur is because the subject is less accurate in reading the questions. The subject identified the problem quickly without understanding the question carefully. In solving the problem, the subject uses a shortcut to solve the problem that is about letting value $b$ whereas precisely the value of $b$ to look for. To be able to solve the problem well students must understand the problem. As with the response of the subject on $\mathrm{K} 2$, it is classified by letting the characteristic of variables and coefficients. Here are the answers to the subject of $\mathrm{K} 2$.

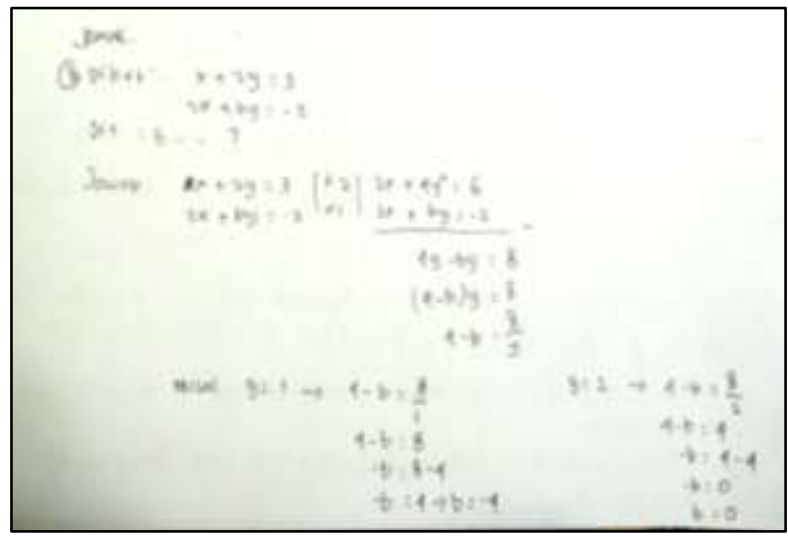

Fig.2.Subjectis classified as Letting characteristic variables and coefficients

From the subject's answer in $\mathrm{K} 2$, at the first stage the subject eliminates the variable $\mathrm{x}$ by multiplying equation one by 2 and multiplying equation two by 1 , then subtracting the result of the equation of equation 1 with the result of the multiplication of equation 2 to obtain a new equation that is $4 \mathrm{y}-\mathrm{by}=8$. Phase next, the subject letting $\mathrm{b}=0$ and $\mathrm{y}=2$. Then substitute the value $\mathrm{b}=0$ and $\mathrm{y}=2$ into the equation $4 \mathrm{y}$ - $b y=8$. Then proves that the value $b=0$ and $y=2$ is true.

Based on the interview subject on $\mathrm{K} 2$, data showed that the subjects read the questions carefully, to simplify the equation subject to use elimination. Subject Letting $b=0$ and $\mathrm{y}=2$ to make it easier to solve problems. Subjects did not understand that the value of $b$ to be sought, not to be exemplified. Here are excerpts from an interview with a subject on $\mathrm{K} 2$.

$\mathrm{P}$ : from the answers, why are you letting $\mathrm{b}=0$ and $\mathrm{y}=2$ ?

$\mathrm{S}$ : to make it accessible in completing the question.

P: to determine the coefficients and variables of a system of linear equations, if allowed in for example?

$\mathrm{S}$ : isn't allowed right mam... (smiling)

From the results of the answers and interviews on the subject K 2, it can be seen that the subject already understood the intent of the question. Errors that do occur subject because it does not understand that to find the coefficients of the variables may not use the analogy. Subjects did it because of the subject of seeking ways to solve well. The subject does not solve the problem according to the appropriate procedure. The error that occurs on $\mathrm{K} 1$ and $\mathrm{K} 2$ subject is different from the error made by the subject on K3. Below are the answers of the subject $\mathrm{K} 3$.

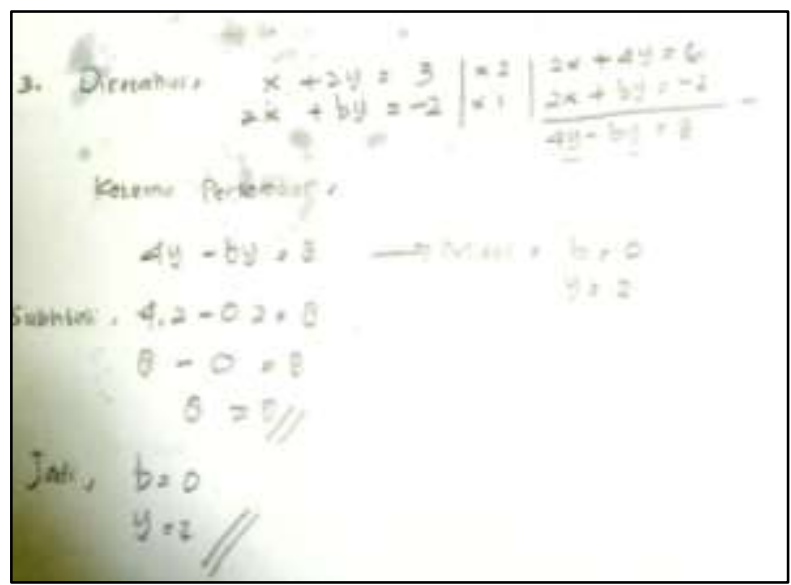

Fig. 3. Letting characteristics classified subject variables to find the coefficient.

From the answers to the subject in K3, at an early stage the subject of eliminating the variable $\mathrm{x}$ by multiplying the first equation by 2 and multiplying the equation 2 to 1 . Then subtracting the result of multiplying equation 1 and the theoretical equation 2 to obtain a new equation which $4 \mathrm{y}-$ by $=8$. Phase next, the subject letting $\mathrm{y}=1$ and $\mathrm{y}=2$ and then substituting $\mathrm{y}=1$ and $\mathrm{y}=2$ equation $4 \mathrm{y}-\mathrm{by}=8$ for resulting value $b=-4$ and $b=0$.

Based on the interview subject on K3 data showed that the subject matter of repeated re-read to understand the intent of the question. To simplify the equation subject, it uses elimination. Subject presuppose $y=1$ and $y=2$ to find the value of $b$. In searching for value $b$, the subject does not 
complete with the appropriate procedure. Subjects did not know that the substitute variable coefficients are not only two, but there are others, and the number was not up. Here are excerpts from an interview with the subject at $\mathrm{K} 3$.

Q: Why do you suppose $\mathrm{y}=1$ and $\mathrm{y}=2$ ?

$\mathrm{S}$ : to find the value of $\mathrm{b}$.

$\mathrm{Q}$ : is it only $\mathrm{y}=1$ and $\mathrm{y}=2$ that can be used to find the value of $b$ ?

S: no mam ... there are still many others.

Q: means exactly how much b that you can find? P: there are many of them right mam ... (in a low voice)

From the results of the answers and interviews on the subject $\mathrm{K} 3$, it is noticeable that subject already understand the intent of the problem well. Errors made the subject occur because the subject does not realize that substitute the variable coefficients of the system of linear equations least two grades but the number was not up. The subject does not resolve the problem according to the appropriate procedure, so it does not find $b$ values based on the requirements of the problem that is asked by the prompt.

\section{CONCLUSION}

This paper has given an account of students' errors in solving problems in the representation of semiotic presented in algebraic representation. The error that the students are doing is the students do not understand the purpose of the problem, and the subject does not understand that to find the coefficient of the variable should not use the letting. Students do not realize that substitute the variable coefficients of the system of linear equations least two grades, but the number was not up. Students do not resolve the problem according to the appropriate procedure, so it does not find the coefficient values based on the requirements of the problem. In this study, researchers analyzed student errors in determining variable coefficient linear equations of a system that has a single completion. For further research, it is advisable to examine student error in determining the variable coefficient of a system of linear equations having ends of completeness and having no completion.

\section{REFERENCES}

[1] D. Sandhu,. "Does anyone have any information on the differences between misconceptions and errors in mathematics?" Research Gate., (Online), (http://www.researchgate.net/post/ Does_anyone_have_any_information_on_the_differences_between_ misconceptions and errors in mathematics), 2013

[2] J.K. Lannin, D.D. Barker, \& B.E. Townsend, "How Students View The General Nature of Their Errors," Educational Studies in Mathematics, vol.66, pp 43-59. Springer. 2007

[3] NCTM, Principles and standards for school mathematics, Reston, VA: National Council of Teachers of Mathematics, 2000

[4] S. Ozdemir, \& R.Z. Ayvar, The effect of Dynamic and Interactive Mathematics Learning Environments (DIMLE), supporting multiple representations, on perceptions of elementary mathematics preservice teachers in the problem-solving process. Mevlana International Journal of Education, vol. 3(3), pp. 85-94, 2013

[5] W. Hwang, N. Chen, J. Dung, \& Y. Yang, "Multiple Representation Skills and Creativity Effects on Mathematical Problem Solving using a Multimedia Whiteboard System," Educational Technology \& Society vol.10 (2), pp191-212, 2007
[6] W. Hwang, N. Chen, J. Dung, \& Y. Yang, "Multiple Representation Skills and Creativity Effects on Mathematical Problem Solving using a Multimedia Whiteboard System," Educational Technology \& Society, vol.10(2), pp191-212, 2007

[7] Hoffman, M. H. G. What is a "semiosmotic perspective', and what could it be? Some comments on the contributions to this special issue. Educational Studies in Mathematics, 61, 279-291. 2006.

[8] J.K. Dimmel and P.G. Herbst. "The Semiotic Structure of Geometry Diagrams: How Textbook Diagrams Convey Meaning," Journal for Research in Mathematics Education, vol. 46(2), pp 147-195, 2015

[9] C. Batanero, J.M. Contreras, C. Díaz, E. Sánchez, "Prospective Teachers' Semiotic Conflicts in Computing Probabilities from a TwoWay Table". Mathematics Education, vol.10(1), pp 3-16, 2015

[10] N. Tarasenkova, \& O. Kovalenko, "Content and Semiotic Features of Mathematical Problems Used as a Means of Training the Primary School Education Students". American Journal of Educational Research, Vol. 3(12B), pp 31-35, 2015

[11] N. Tarasenkova, "The Quality of Mathematical Education in the Context of Semiotics". American Journal of Educational Research, Vol. 1(11), pp 464-471, 2013

[12] S. Inganah, \& Subanji. "Semiotik Dalam Proses Generalisasi Pola. KNPM V," Himpunan Matematika Indonesia, pp 431- 438, 2013

[13] S.C. Uzuna, \& Arslan, "Semiotic representations skills of prospective elementary teachers related to mathematical concepts," Procedia Social and Behavioral Sciences vol.1, pp 741-745, 201

[14] J. W. Creswell, Research Desain Pendekatan Kualitatif, Kuantitatif, dan Mixed, Yogyakarta: Pustaka Belajar, 2012 